\title{
E2F-1 regulation by an unusual DNA damage-responsive DP partner subunit
}

\author{
L Ingram ${ }^{1,2}$, S Munro $^{1,2}$, AS Coutts $^{1}$ and NB La Thangue ${ }^{\star, 1}$
}

E2F activity is negatively regulated by retinoblastoma protein $(\mathrm{pRb})$ through binding to the E2F-1 subunit. Within the E2F heterodimer, DP proteins are E2F partner subunits that allow proper cell cycle progression. In contrast to the other DP proteins, the newest member of the family, DP-4, downregulates E2F activity. In this study we report an unexpected role for DP-4 in regulating E2F-1 activity during the DNA damage response. Specifically, DP-4 is induced in DNA-damaged cells, upon which it binds to E2F-1 as a non-DNA-binding E2F-1/DP-4 complex. Consequently, depleting DP-4 in cells re-instates E2F-1 activity that coincides with increased levels of chromatin-bound E2F-1, E2F-1 target gene expression and associated apoptosis. Mutational analysis of DP-4 highlighted a C-terminal region, outside the DNA-binding domain, required for the negative control of E2F-1 activity. Our results define a new pathway, which acts independently of $\mathrm{pRb}$ and through a biochemically distinct mechanism, involved in negative regulation of E2F-1 activity.

Cell Death and Differentiation (2011) 18, 122-132; doi:10.1038/cdd.2010.70; published online 18 June 2010

The E2F family of transcription factors regulate a variety of cellular outcomes, including cell cycle progression, differentiation and apoptosis. ${ }^{1,2}$ The first member of the family to be identified, E2F-1, is a crucial target of the retinoblastoma $(\mathrm{pRb})$ tumour suppressor protein in the control of the G1- to S-phase transition. ${ }^{3,4} \mathrm{pRb}$ physically interacts with DNAbound E2F-1 and thereby prevents transcriptional activity. ${ }^{5}$ In turn, cell cycle progression cannot occur, which is important for $\mathrm{pRb}$ to exert its tumour suppressor activity. ${ }^{5}$ To date, eight E2F subunits have been identified, together with three DP subunits. ${ }^{6}$ E2F-7 and E2F-8, the two most recently characterized members of the family, possess unusual properties, with two DNA-binding domains that allow DNA binding to occur independently of a DP subunit. ${ }^{7-11}$ In mammalian cells, however, most of the E2F exists as a heterodimer in complex with a DP subunit. ${ }^{6}$

Under normal physiological conditions DP-1 is the predominant E2F partner protein. ${ }^{12,13} \mathrm{DP}-1$ is encoded by an essential gene, as $d p-1^{-1-}$ mice show embryonic lethality, in part due to defective extraembryonic tissue development. ${ }^{14}$ Furthermore, DP-1 phosphorylation is regulated during cell cycle progression, and its phosphorylation by cyclinA/cdk2 kinase is believed to be involved in controlling the DNAbinding activity of the E2F heterodimer and exit from $S$ phase. ${ }^{15}$ Another member of the DP family, murine DP-3 (human DP-2), undergoes complex levels of control, and a variety of protein isoforms exist in cells that differ in both biochemical and functional properties. ${ }^{16,17}$ The most recent family member to be described, DP-4, acts negatively on both E2F DNA-binding activity and cell cycle progression. ${ }^{18-20}$

In this study we describe some unexpected properties of the newest member of the DP family, DP-4, and highlight a novel pathway that allows $\mathrm{pRb}$-independent negative control of E2F-1 activity. We have found that DP-4 is DNA damage responsive, which leads to the downregulation of E2F-1 activity by creating an E2F-1/DP-4 complex that cannot bind to DNA. Consequently, depleting DP-4 re-instates E2F-1 DNA-binding activity, which coincides with increased expression of a variety of E2F-1 target genes and enhanced levels of apoptosis. Significantly, a domain that resides in the C-terminal region of DP-4 is responsible for downregulating E2F-1 activity. Our results define a new pathway, which acts independently of $\mathrm{pRb}$ and through a biochemically distinct mechanism, to regulate E2F-1 activity.

\section{Results}

DP-4 is DNA damage responsive. An analysis of DP-4 using a DP-4-specific antibody indicated that it is a nuclear protein expressed in a variety of different cancer cell lines (Figure 1a-c; Supplementary Figure 1a and b). In characterizing the properties of DP-4, we considered that its expression might be influenced by DNA damage. DP-4 was DNA damage inducible in different cell types (U2OS, HeLa, MCF7, HEK293 and H1299) treated with doxorubicin,

${ }^{1}$ Laboratory of Cancer Biology, Department of Clinical Pharmacology, University of Oxford, Old Road Campus Research Building, Old Road Campus, off Roosevelt Drive, Oxford, OX3 7DQ, UK

${ }^{*}$ Corresponding author: NB La Thangue, Department of Clinical Pharmacology, Laboratory of Cancer Biology, Old Road Campus Research Building, Old Road Campus, off Roosevelt Drive, Oxford, OX3 7DQ, UK. Tel: + 441865 61 7090; Fax: + 44186561 7092; E-mail: nick.lathangue @ clinpharm.ox.ac.uk

${ }^{2}$ These two authors contributed equally to this work.

Keywords: cell cycle; E2F-1; DP-4; repression; DNA damage

Abbreviations: pRb, retinoblastoma protein; siRNA, small interfering RNA; PARP, poly (ADP-ribose) polymerase; PCNA, proliferating cell nuclear antigen; UV, ultraviolet light; Apaf1, apoptotic protease-activating factor 1; NT, non-targeting; NS, nonspecific; ChIP, chromatin immunoprecipitation; DMEM, Dulbecco's modified Eagle medium; FBS, fetal bovine serum

Received 26.11.09; revised 02.4.10; accepted 07.5.10; Edited by V De Laurenzi; published online 18.6.10 
a

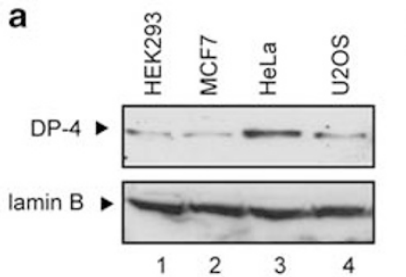

c

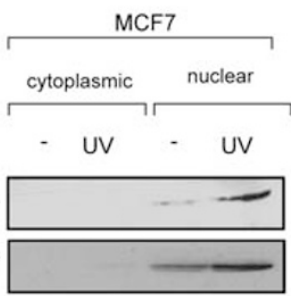

d

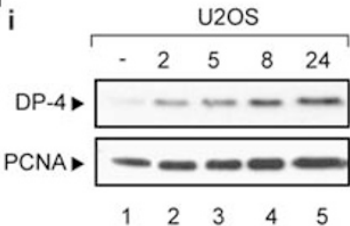

ii
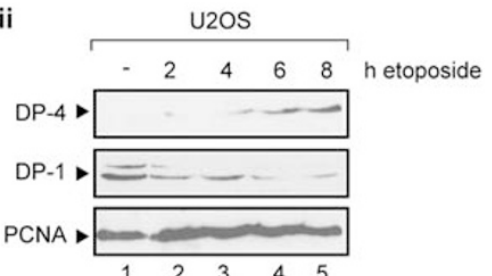

iii

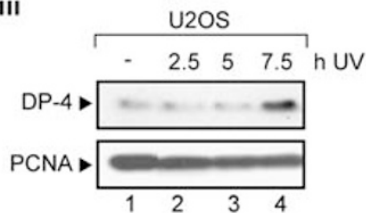

b $\quad$ DP-4

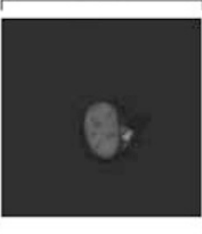

e

$$
\text { i }
$$

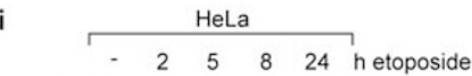

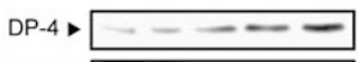

PCNA

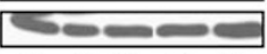

$\begin{array}{lllll}1 & 2 & 3 & 4 & 5\end{array}$

ii
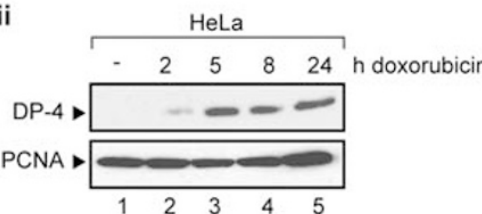

iii

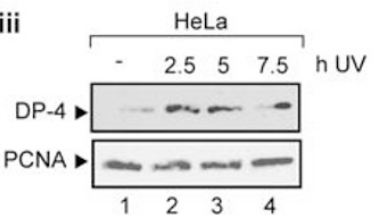

g
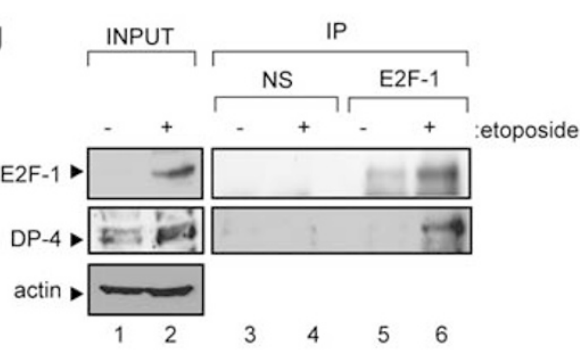

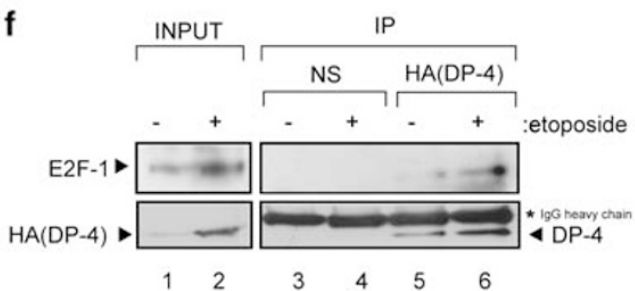

Figure 1 DP-4 is DNA damage inducible. (a) Endogenous DP-4 in HEK293, HeLa, MCF7 and U2OS cells: cell extract (100 $\mu \mathrm{g}$ ) prepared from each cell type was immunoblotted with peptide-purified anti-DP-4 antibody; lamin B served as the loading control. (b) U2OS cells were transfected with expression vector encoding HA-DP-4 $(1 \mu \mathrm{g})$. Immunostaining was performed with anti-HA11 or peptide-purified anti-DP-4 antibody as described; DAPI was used to visualize nuclei. (c) MCF7 cells were treated with ultraviolet (UV) light $\left(50 \mathrm{~J} / \mathrm{m}^{2}\right)$. After $8 \mathrm{~h}$, cells were fractionated into cytoplasm and nuclei, and thereafter immunoblotted with anti-DP-4 or anti-nucleophosmin as indicated, the latter serving as a control for nuclear fraction. (d, i) U2OS cells were treated with doxorubicin $(2 \mu \mathrm{M})$ for 2, 5, 8 and $24 \mathrm{~h}$ and extracts immunoblotted with anti-DP-4 antibody; PCNA served as the loading control. (d, ii) U2OS cells treated with etoposide $(10 \mu \mathrm{M})$ for $2,4,6$ or $8 \mathrm{~h}$ and extracts immunoblotted with the indicated antibodies; PCNA served as the loading control. (d, iii) U2OS cells were treated with ultraviolet (UV) light $\left(50 \mathrm{~J} / \mathrm{m}^{2}\right)$, extracts prepared at 2.5, 5.0 and $7.5 \mathrm{~h}$ and immunoblotted with anti-DP-4; PCNA served as the loading control. (e, i) HeLa cells were treated with etoposide $(10 \mu \mathrm{M})$ for 2, 5, 8 and $24 \mathrm{~h}$ and extracts immunoblotted with anti-DP-4 antibody; PCNA served as the loading control. (e, ii) HeLa cells were treated with doxorubicin $(2 \mu \mathrm{M})$ for 2, 4, 6 or $8 \mathrm{~h}$ and extracts immunoblotted with the indicated antibodies; PCNA served as the loading control. (e, iii) HeLa cells were treated with ultraviolet (UV) light $\left(50 \mathrm{~J} / \mathrm{m}^{2}\right)$, extracts prepared at $2.5,5.0$ and $7.5 \mathrm{~h}$ and immunoblotted with anti-DP-4; PCNA served as the loading control. (f) U2OS cells were transfected with HA-DP-4 $(1 \mu \mathrm{g})$, and $44 \mathrm{~h}$ later cells were treated with etoposide $(10 \mu \mathrm{M})$ and left for $4 \mathrm{~h}$, harvested, immunoprecipitated with anti-HA11 or a nonspecific (NS) antibody and the immunoprecipitates immunoblotted with anti-E2F-1 and HA11 (DP-4) antibody. DP-4 is indicated by the arrow, together with the NS IgG heavy chain. (g) U2OS cells were treated with etoposide (10 $\mu \mathrm{M})$, left overnight, harvested and immunoprecipitated with anti-E2F-1 (KH95) or NS antibody. The immunoprecipitates were immunoblotted with anti-E2F1 and anti-DP-4 

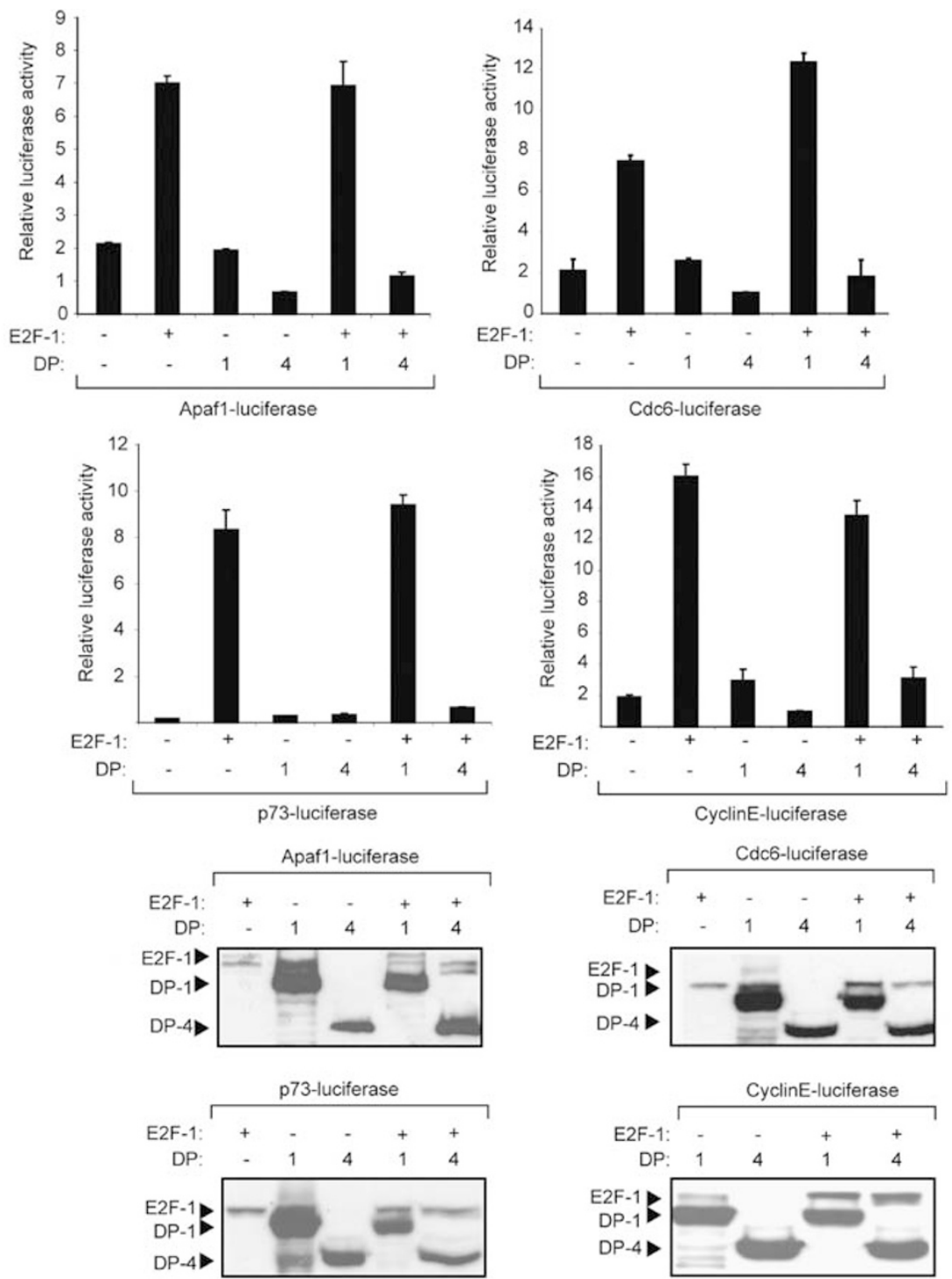

b

C
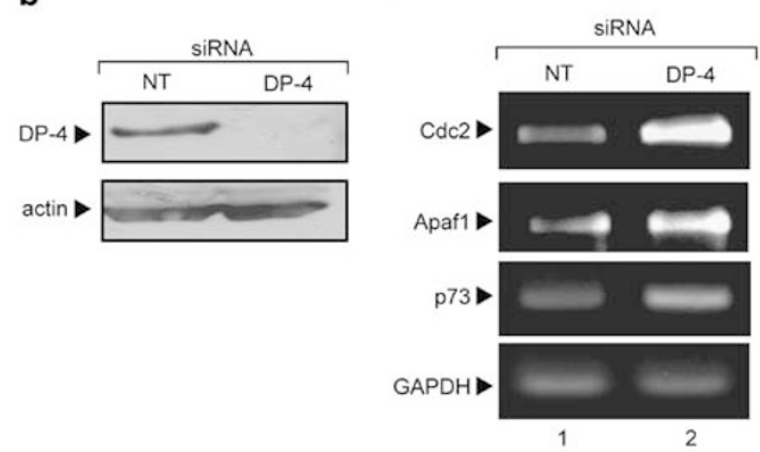

d

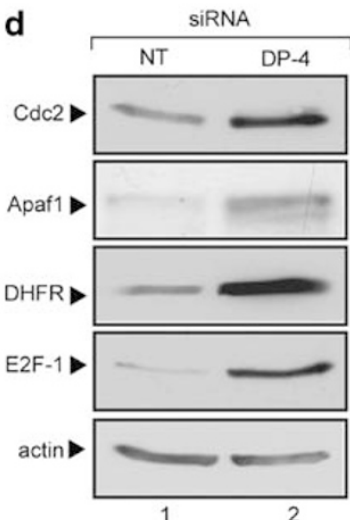

Figure 2 DP-4 downregulates E2F site-dependent transcription. (a) U2OS cells were transfected with the indicated expression vectors (1 $\mu \mathrm{g}$ ) as described and the effect on Apaf1-luciferase, Cdc6-luciferase, p73-luciferase and cyclinE-luciferase was measured. The luciferase activity is shown (relative to co-transfected pCMV- $\beta$ gal expression), and lower panels show the level of ectopic proteins for each experiment. (b) U2OS cells were treated with non-targeting (NT) or DP-4 siRNA as described followed by immunoblotting; actin served as the loading control. (c) U2OS cells were transfected with DP-4 or NT control siRNA (25 nM) as described. After $72 \mathrm{~h}$, cells were harvested, RNA extracted, reverse transcribed and the level of Cdc2, Apaf1, p73 and GAPDH RNA was assessed. (d) U2OS cells were transfected with DP-4 or NT control siRNA $(25 \mathrm{nM})$ as described. After $72 \mathrm{~h}$, cells were harvested and extracts immunoblotted with antibodies against Cdc2, Apaf1, DHFR, E2F-1 and actin 
etoposide and ultraviolet (UV) light (Figure 1c-f; Supplementary Figure 1c and d), contrasting with DP-1 that was not induced by DNA damage (see, e.g., Figure 1d). Endogenous DP-4 was located in nuclei, although under DNA damage conditions there was a significant increase in protein level and nuclear staining intensity (Figure 1c and Supplementary Figure 1e). Although a significant increase was observed at the protein level, DP-4 mRNA levels only underwent a modest increase after DNA damage (Supplementary Figure 1f). Furthermore, the DNA damagedependent increase in DP-4 protein levels reflected increased levels of the DP-4/E2F-1 heterodimer when either the ectopic or endogenous proteins were measured (Figure $1 \mathrm{f}$ and $\mathrm{g}$ ). These results therefore establish that DP-4 is DNA damage responsive, and that, in addition, DNA damage favours formation of the E2F-1/DP4 heterodimer.

To examine the effect of DP-4 on transcription, we tested the functional consequences of DP-4 expression on a collection of E2F-responsive promoters, namely apoptotic protease-activating factor 1 (Apaf1), Cdc6, p73 and cyclin E. 5,21 Although each promoter was activated by E2F-1, coexpressing DP-4 resulted in reduced levels of transcription (Figure 2a). The effect of DP-4 contrasted with DP-1, which augmented transcription (Figure $2 \mathrm{a}$ ); ectopic protein levels were expressed as expected in transfected cells (Figure 2a). Thus, DP-4 inactivates transcription, and has the opposite effect compared with DP-1 on E2F site transcription.

To establish that the effect of ectopic DP-4 recapitulated effects on endogenous genes, we used small interfering RNA (siRNA) to deplete endogenous DP-4, and thereafter monitored the effect on E2F target genes. Under conditions of DP-4 depletion (Figure 2b), the levels of both RNA and protein encoded by different E2F target genes, including Cdc2, Apaf1, p73 and E2F-1, increased (Figure 2c and d). Thus, DP-4 is a negative regulator of E2F target genes.
DP-4 hinders E2F-1 DNA binding. To address the mechanisms responsible for downregulating E2F activity, we considered that DP-4 might compete with DP-1 for binding to the E2F subunit. Under conditions in which E2F-1 and DP-1 were able to activate transcription, there was a titratable decline in transcription as the level of DP-4 increased (Figure 3a). Conversely, the downregulation of E2F transcription by DP-4 could be overcome by increasing the level of DP-1 (Figure $3 b$ ). These results suggest that DP-4 acts competitively with DP-1.

We next investigated whether the integrity of the DP-4 DNAbinding domain was necessary for DP-4 to downregulate E2F site transcription. We tested this possibility by manipulating DP-4 in two ways. First, we removed the conserved and essential RRXYD DNA-binding consensus motif (RRTYD in DP-4; Figure $4 a$ and $b$ ) to create a DP-4 derivative that was defective in DNA binding $(\Delta 162-166)$. Second, an alignment of DP-1 with DP-4 highlighted a number of subunit-specific amino acid residues within the DNA-binding and dimerization domains (Figure $4 a$ and $b$ ) that, from inspection of the structure of the E2F heterodimer, ${ }^{22}$ might be expected to influence DNA-binding activity (Figure 4a). We therefore prepared a series of derivatives in which each one of the different residues was serially substituted into DP-4 (the DP-1 residue replacing each of the different DP-4 residues), eventually giving rise to the DP $-4 * 4$ in which all the relevant DP-1-specific residues were transferred into DP-4 (Figure 4b). Each mutant derivative was subsequently tested for its ability to downregulate E2F site-dependent transcription. Neither DP-4 $\Delta 162-166$ nor any of the DP-4 derivatives were compromised in their ability to downregulate transcription, and each mutant was expressed at a similar level (Figure 4c and d). The fact that DP-4 $\Delta 162-166$, which lacks residues that are essential for DNA binding, ${ }^{22}$ retained the ability to downregulate transcription strongly suggests that
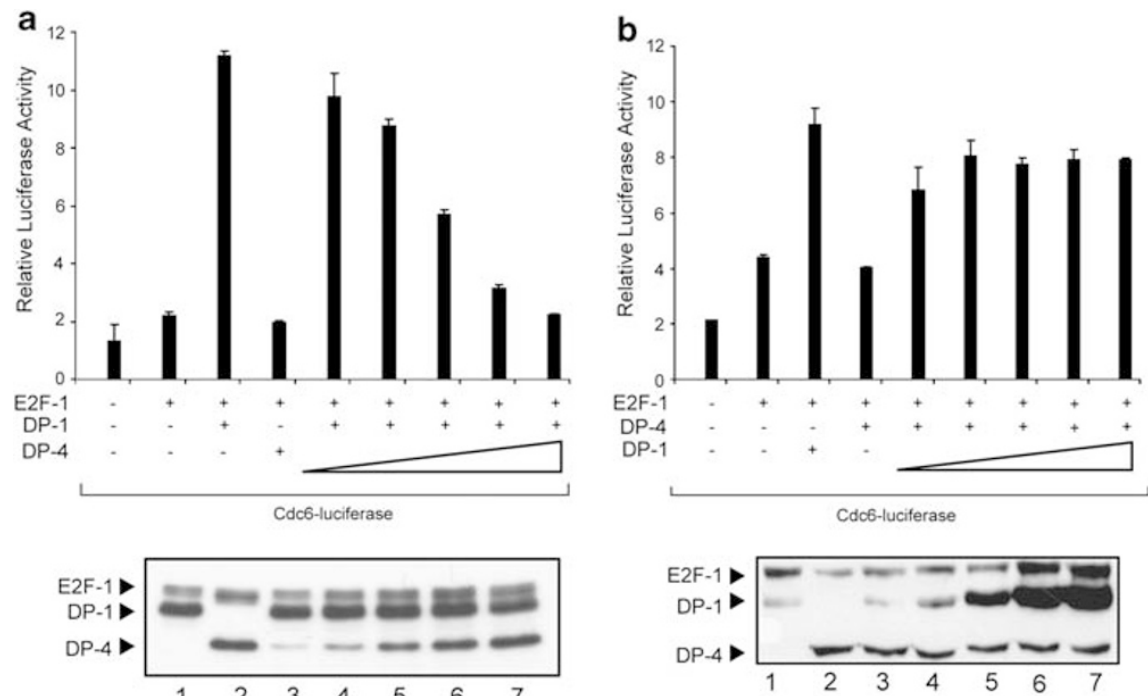

Figure 3 DP-4 competes with DP-1 to downregulate E2F site transcription. (a) U2OS cells were transfected with Cdc6-luciferase ( $1 \mu \mathrm{g})$, together with expression vectors for E2F-1 $(100 \mathrm{ng})$, with DP-4 transfected in increasing amounts $(0.1,0.2,0.5,1.0$ and $2.0 \mu \mathrm{g})$ in the presence of a constant level of DP-1 $(2 \mu \mathrm{g})$. The relative luciferase activity is shown together with the level of ectopic protein in the lower panel. (b) U2OS cells were transfected with Cdc6-luciferase (1 $\mu \mathrm{g})$, together with expression vectors for E2F-1 (100 ng), with DP-1 transfected in increasing amounts $(0.1,0.2,0.5,1.0$ and $2.0 \mu \mathrm{g})$ in the presence of a constant level of DP-4 $(2 \mu \mathrm{g})$. The relative luciferase activity is shown together with the level of ectopic protein in the lower panel 
a

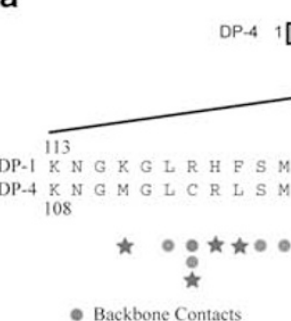

Backbone Contacts

- Dimerisation Contacts

C
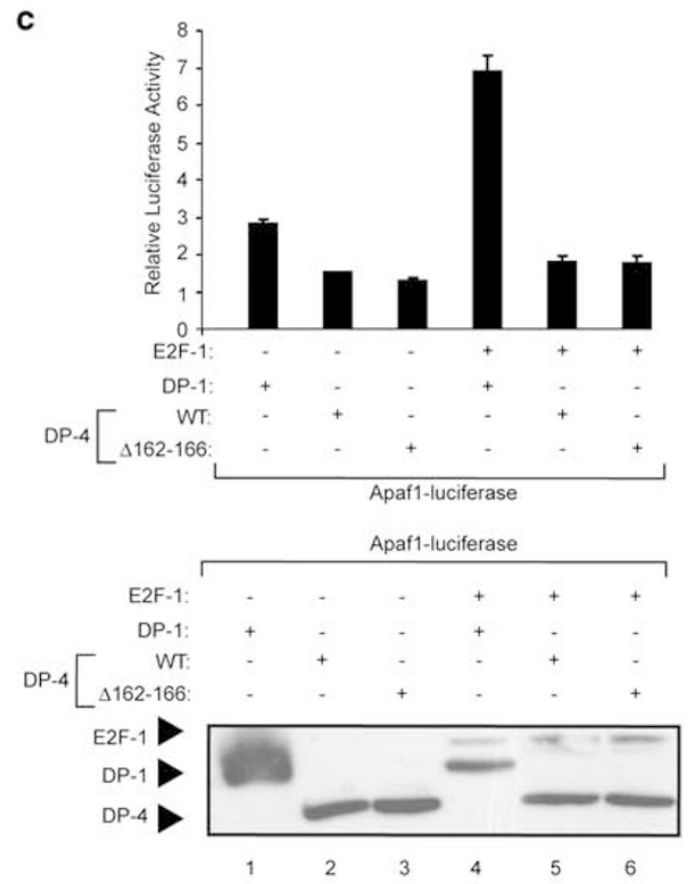

d
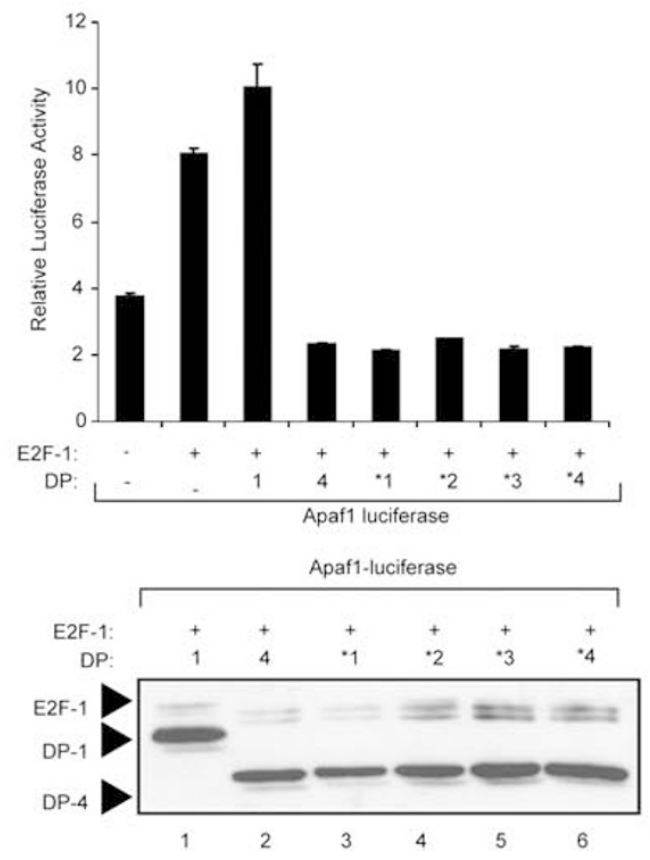

b

DP-1 GEKNGKGLRHFSMKVCEKVQ DP-4 GEKNGMGLCRLSMKVWETVQ DP $-4 \star 2$ GEKNGMGLRRLSMKVWETVO DP- $4 * 3$ GEKNGKGLRHFSMKVCEKVQ DP $-4 \star 4$ GEKNGKGLRHFSMKVCEKVQ

SAYDOKNIRRRVYDALNVI SAYDVKNIKRRTYDALNVI SAYDVKNIKRRTYDALNVI SAYDVKNIKRRTYDALNVI SAYDOKNIRRRVYDALNVI SAYDOKNIRRRTYDALNVI SAYDQKNIRRRVYDALNVI SAYDVKNIK ALNVL DP-4A1 GEKNGKGLRHESMKVWETVQ DP- $4 * 1$ GEKNGKGLRRLSMRVCEKVQ $\begin{array}{ll}\text { DP }-4 \star 4 & \text { GEKNGKGLRHFSMKVCEKVQ } \\ \text { DP }-4 \Delta & \text { GEKNGMGLCRLSMKVWETVQ }\end{array}$
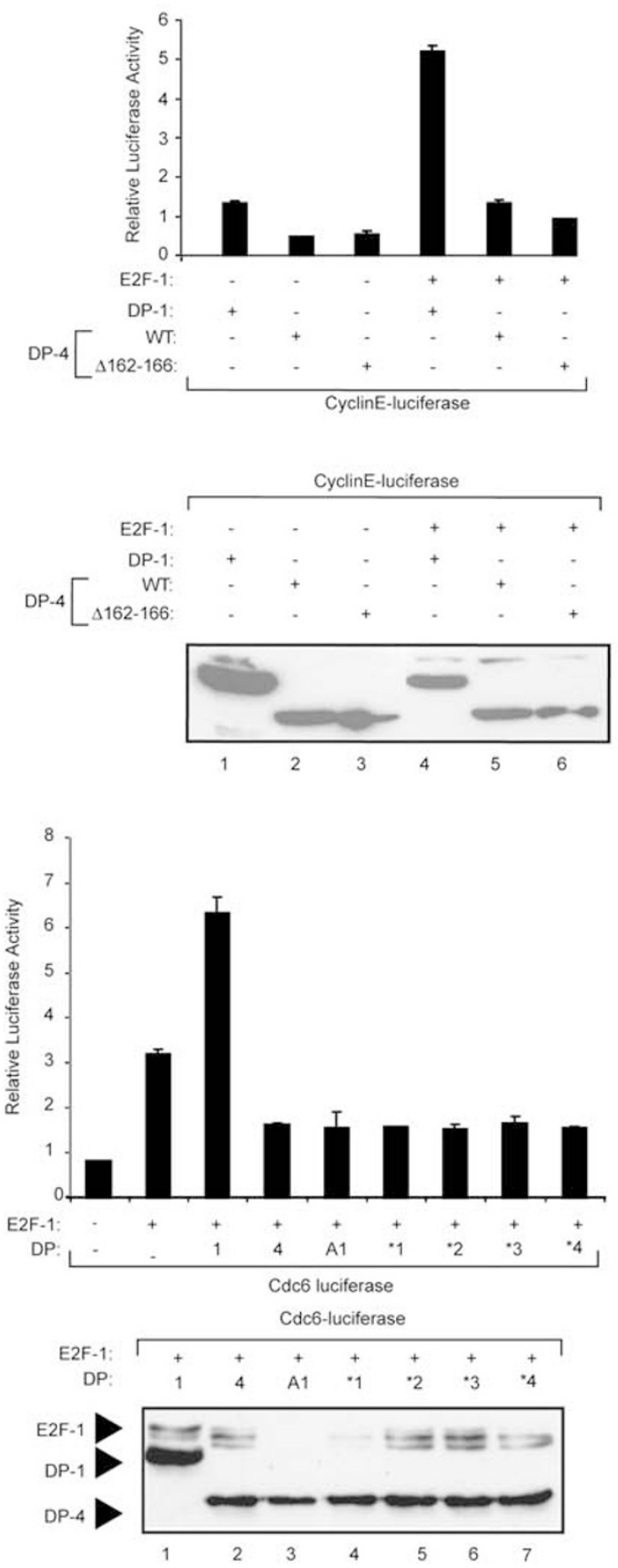
DNA binding is not necessary for the effects of DP-4 on E2F site transcription. This idea is consistent with the properties of the DP-4 substitution mutants (Figure $4 d$ ) that similarly were able to downregulate transcription. Overall, DP-4 downregulates E2F site transcription in a manner that does not require the integrity of the DNA-binding domain.

We prepared a series of DP-4 deletion mutants to identify the domain in DP-4 that is responsible for the control of E2F activity. Derivatives lacking the N-terminal region of DP-4, up to residue 174, which removed the DNA-binding and dimerization domain (Figure $5 \mathrm{a}$ ), could downregulate transcription (Figure $5 \mathrm{~b}$ and $\mathrm{c}$ ). Furthermore, although a C-terminal deletion up to residue 306 could downregulate E2F-1 activity, further deletion up to residue 206 diminished this activity, and a deletion up to residue 106 completely abolished this activity (Figure $5 \mathrm{a}$ and b). Significantly,

a

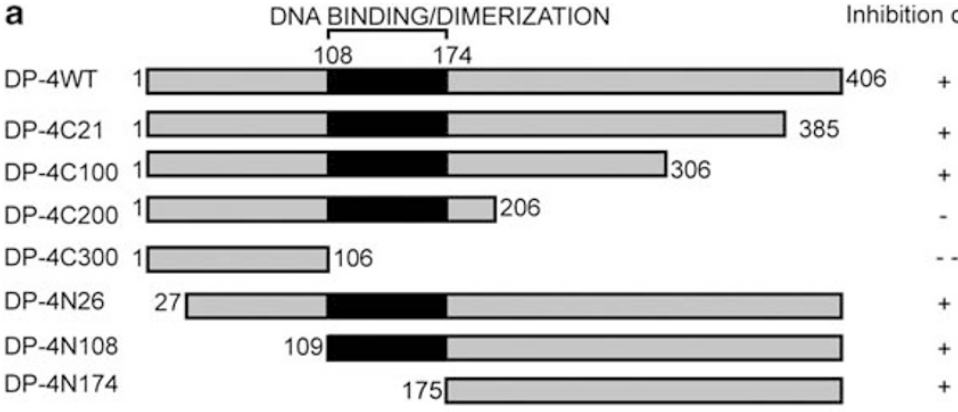

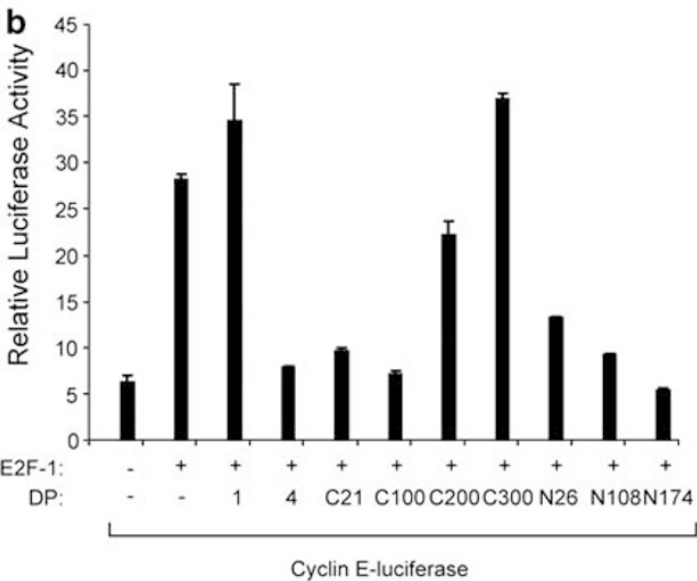

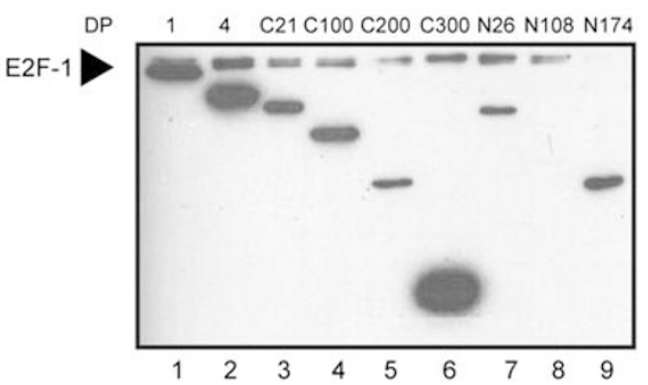

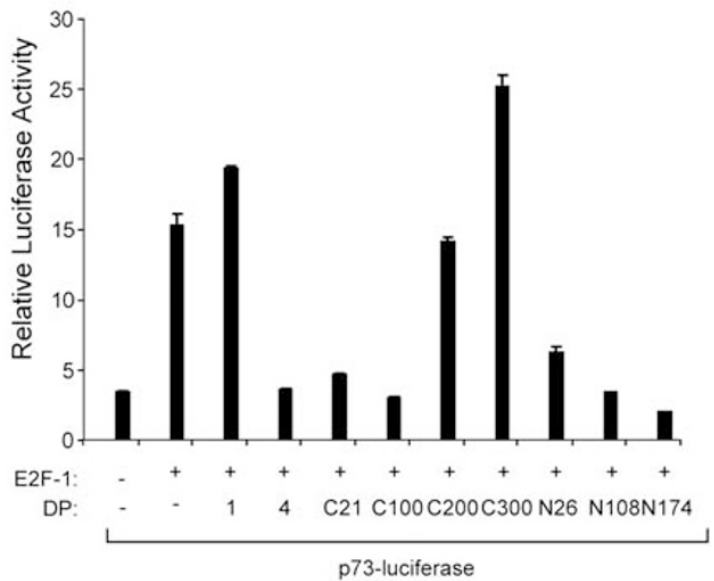

DP $1 \quad 4 \quad$ C21 C100 C200 C300 N26 N108 N174

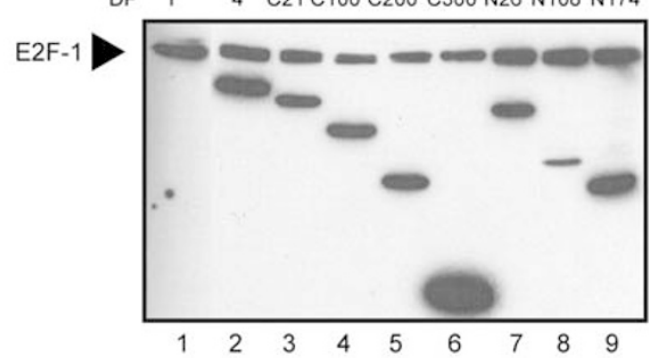

Figure 5 Properties of DP-4 deletion mutants. (a) Schematic representation of the DP-4 derivatives used in (b) and (c), and a summary of their ability to downregulate E2F-1 activity. (b) U2OS cells were transfected with expression vectors encoding the indicated DP-4 derivatives together with E2F-1, and the effect on the cyclin E-luciferase and p73-luciferase activity was measured. Lower panels show the levels of the ectopic proteins. (c) U2OS cells were transfected with expression vectors encoding E2F-1 or DP-1, together with increasing amounts of DP-4N174 $(0.1,0.2,0.5,1.0$ or $2.0 \mu \mathrm{g})$, and the effect on Cdc6-luciferase was measured. The level of ectopic protein is shown in the lower panel

Figure 4 Properties of DP-4 mutant derivatives. (a) Outline organization of DP-4, and an alignment of DP-1 and DP-4 across the DNA-binding domain (amino acid residues 108 to 174) indicating the residues important for contacting DNA (red and black circles) and dimerization (green circles; taken from Zheng et al. ${ }^{22}$ ). Residues that differ between DP-1 and DP-4 are indicated by blue (*). (b) Details of the substitution mutants generated in DP-4; the highlighted (red) amino acid residues were introduced into the DP-4 sequence. DP-4 $\Delta 162-166$ shows the details of the DNA-binding deletion mutant, in which the conserved DNA-binding motif RRTYD has been deleted. (c) U2OS cells were transfected with expression vectors encoding wild-type DP-4 or $\Delta 162-166$ together with E2F-1 or DP-1 as indicated, and the effect on Apaf1-luciferase and cyclin E-luciferase was measured. Lower panels show levels of ectopic proteins. (d) U2OS cells were transfected with expression vectors, encoding wild-type DP-4 or the indicated DP-4 substitution mutants, together with E2F-1 or DP-1 as indicated, and the effect on Apaf1-luciferase and Cdc6-luciferase reporters was measured. Lower panels show levels of ectopic proteins. The colour reproduction of this figure is available on the html full text version of the manuscript. (The color reprodution of the figure is available on the html full text version of the paper) 


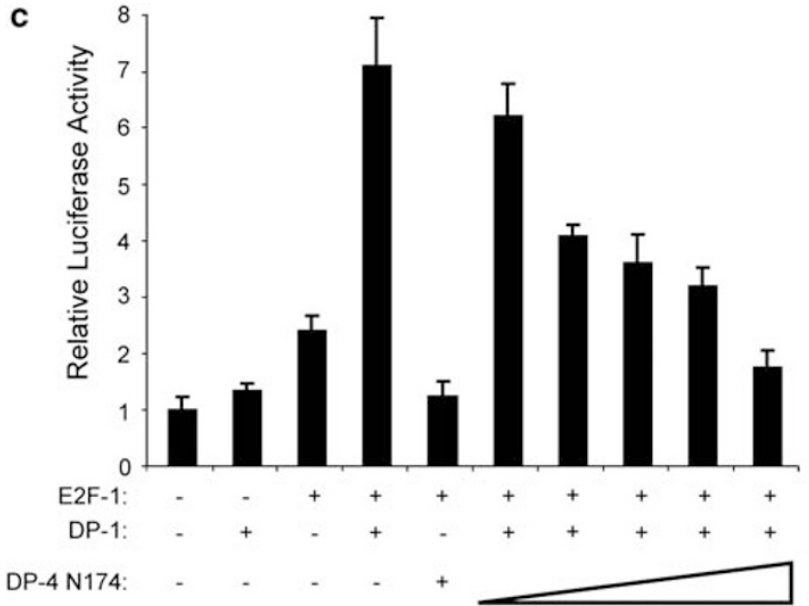

Cdc6-luciferase

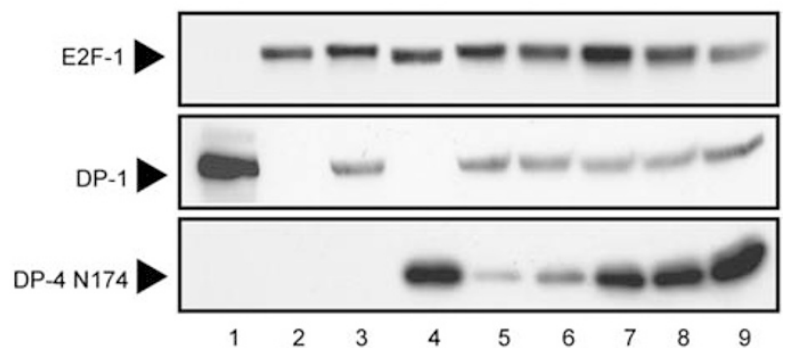

Figure 5 Continued

DP-4N174, which lacks DNA-binding activity, could compete with DP-1 for E2F-1 activity (Figure $5 \mathrm{c}$ ). These results suggest that the region required for DP-4 to downregulate E2F site transcription lies between residue 175 and 306 . As the DNA-binding and dimerization domain resides between residue 108 and 174, these results further confirm that DP-4 DNA-binding and dimerization activity is unlikely to be involved in the effects on E2F activity. This idea is consistent with the properties of DP-4 N174, which lacks DNA-binding and dimerization activity but retains the ability to reduce transcriptional activation when coexpressed with E2F-1/DP-1 (Figure 5c).

DP-4 hinders E2F DNA-binding activity. However, it remained possible that DP-4 affects the DNA-binding activity of E2F-1, which we tested by assessing the effect of DP-4 on chromatin-bound E2F-1. First, we monitored the effect of ectopic DP-4 on E2F-1 activity by chromatin immunoprecipitation (ChIP) and, second, the effect of DP-4 siRNA on chromatin-bound endogenous E2F-1. Although ectopic DP-1 was detected on the promoter of the E2F-1 and Cdc2 genes, ectopic DP-4 was not (Figure 6a), despite expression of equivalent levels of the ectopic protein (Figure 6a, iii). The effect of DP-4 on E2F-1 contrasted with DP-1, which enhanced E2F-1 binding (Figure 6a). Frequently, ectopic DP-4 even reduced E2F-1 binding to $\mathrm{E} 2 \mathrm{~F}$ target genes (e.g., the E2F-1 promoter; Figure 6a). These results suggest that DP-4 fails to locate to the chromatin of E2F target genes, which is compatible with the earlier results indicating that DNA binding is not required for the transcription effects of DP-4.

To test whether endogenous DP-4 behaved in a similar manner with the ectopic protein, we performed a ChIP analysis on DP-4 siRNA-treated cells (Figure 6b). Under conditions of DP-4 depletion, E2F-1 underwent increased binding to the promoters of E2F target genes, in both unperturbed and DNA-damaged cells (Figure $6 \mathrm{~b}$ and $\mathrm{c}$ ). These results support the data obtained with ectopic DP-4 (Figure 6a), and suggest that endogenous DP-4 downregulates the expression of E2F target genes through modulating access of E2F-1 to chromatin.

Physiological role of DP-4. Given the induction of DP-4 under DNA damage conditions, together with its ability to downregulate E2F-1 activity, we reasoned that DP-4 may take on an important role in mediating the cell cycle effects of DNA damage. This possibility was tested by depleting endogenous DP-4 and thereafter analysing the effect on cell cycle progression. In different cell types (U2OS and SAOS2), depletion of DP-4 caused a decrease in the population of G1 cells, with increased levels of S and G2/M cells (Figure 7a and c; Supplementary Figure 1g). In contrast, under DNA damage conditions, reduced levels of DP-4 coincided with a dramatic increase in sub-G1 (0.79 to $18.4 \%$ ), together with a decreased population of $\mathrm{G} 1$ cells (Figure $7 \mathrm{a}$ and $\mathrm{c}$ ). These results suggest that DP-4 influences cell cycle progression, under both normal and DNA damage conditions.

Furthermore, as E2F-1 activity increases in DP-4 siRNAtreated cells, and because E2F-1 can induce apoptosis, ${ }^{23,24}$ we tested the effect of DP-4 on E2F-1-induced apoptosis. There was a reduction in the level of apoptosis (measured as poly (ADP-ribose) polymerase (PARP) cleavage) when DP-4 was coexpressed with E2F-1 (Figure 7d). Overall, therefore, DP-4 is functionally involved in regulating cell cycle progression as well as the outcome of the DNA damage response.

\section{Discussion}

DP-4 and the DNA damage response. An important property that distinguishes DP-4 from other members of the DP family is the ability to downregulate transcription, and its induction during the DNA damage response. Most interestingly, DP-4 carries a domain in the C-terminal region that is responsible for downregulating transcription in a manner that is independent of DNA-binding domain. The idea that DP-4 DNA-binding activity is not required to downregulate transcription is compatible with the absence of DP-4 on the promoters of E2F target genes, even in conditions of ectopic protein expression. It is most likely therefore that DP-4 interacts with E2F-1 in a manner that prevents E2F-1 binding to the promoters of target genes (Figure 7e).

By studying cells in which DP-4 had been depleted, it was apparent that DP-4 regulates the $\mathrm{G} 1$ population and contributes to the cell cycle arrest that occurs upon DNA damage. The increased population of apoptotic sub-G1 cells upon 

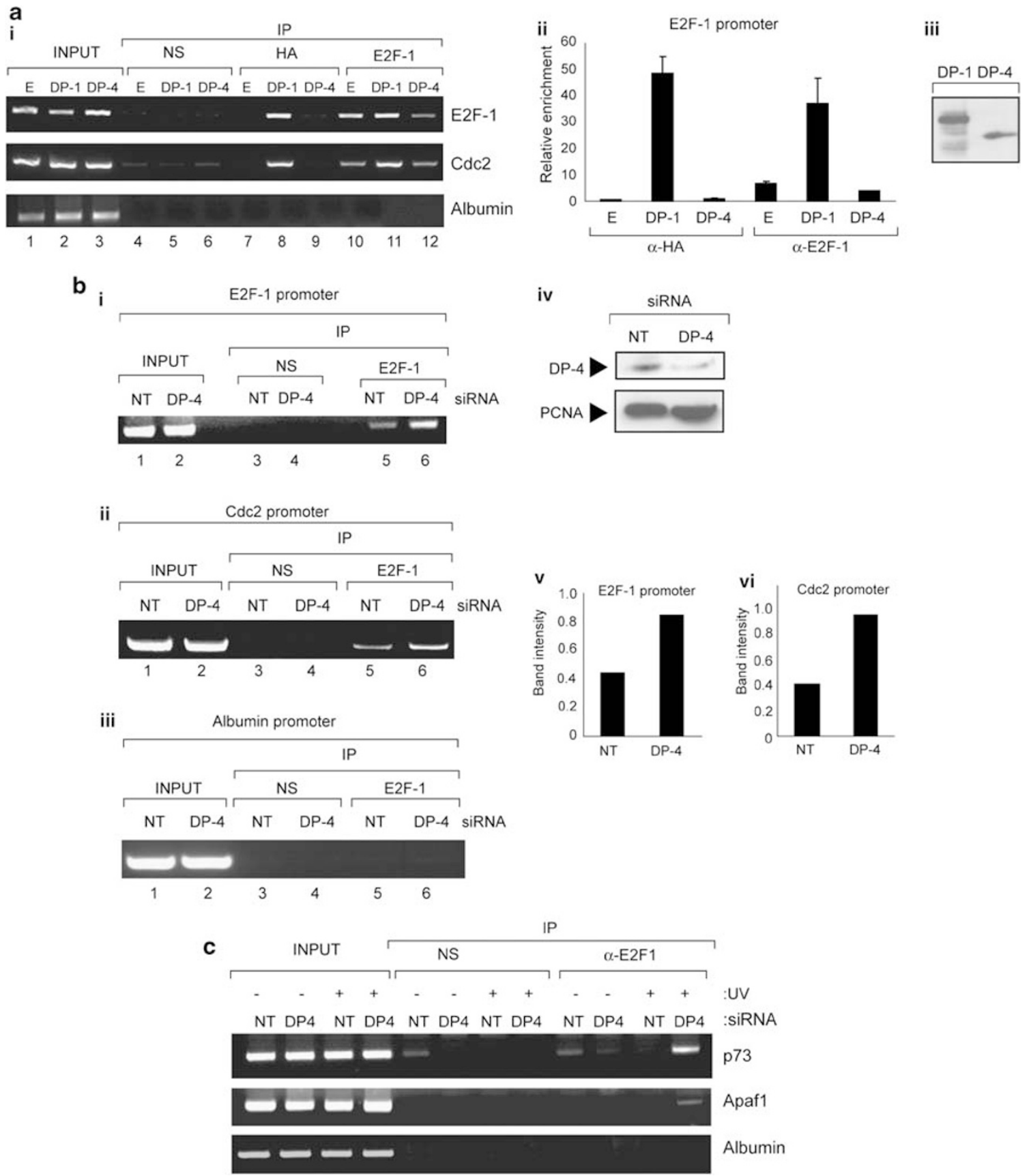

Figure 6 DP-4 regulates chromatin-bound E2F-1. (a, i) U2OS cells were transfected with expression vectors $(1 \mu \mathrm{g})$ encoding HA-DP-1, HA-DP-4 or empty vector (E) as indicated. After $48 \mathrm{~h}$, chromatin was prepared and ChIP analysis performed using anti-HA, E2F-1 or a nonspecific (NS) antibody control, and binding to the E2F-1, Cdc2 and albumin promoters was assessed as described. (a, ii) Quantification of the ChIP analysis in (i) by real-time PCR. (a, iii) Levels of the ectopic proteins, immunoblotted with anti-HA antibody. (b, i) U2OS cells were treated with DP-4 or non-targeting (NT) siRNA (25 nM). After $48 \mathrm{~h}$, chromatin was prepared and ChIP analysis was performed using anti-E2F-1 or NS antibody control as described above. Binding to the E2F-1 (i), Cdc2 (ii) and albumin control (iii) promoter was assessed as described. (iv) Protein levels in cells treated as described in (i) was assessed by immunoblotting with anti-DP-4 and anti-PCNA. (v, vi) Quantification of E2F-1 binding on the E2F-1 and Cdc2 promoters, respectively. (c) U2OS cells were treated with DP-4 or NT siRNA ( $25 \mathrm{nM})$. After $48 \mathrm{~h}$, cells were treated with ultraviolet (UV) light $\left(50 \mathrm{~J} / \mathrm{m}^{2}\right)$. After $8 \mathrm{~h}$, chromatin was prepared and ChIP analysis performed using anti-E2F-1 or NS antibody control. Binding to the p73, Apaf1 and albumin promoters was assessed

depleting DP-4 is consistent with a role for DP-4 in assisting cell survival upon DNA damage. Furthermore, the level of E2F-1-dependent apoptosis was reduced in the presence of DP-4, suggesting that DP-4 activity antagonizes apoptosis driven by E2F-1. The ability of DP-4 to augment the G1 population in both unperturbed and DNA-damaged cells might therefore reflect decreased E2F-1 activity, and consequently reduced apoptosis (Figure 7e). Together, our results suggest that DP-4 is a functionally distinct member of the DP family, with the ability to negatively regulate E2F-1. 

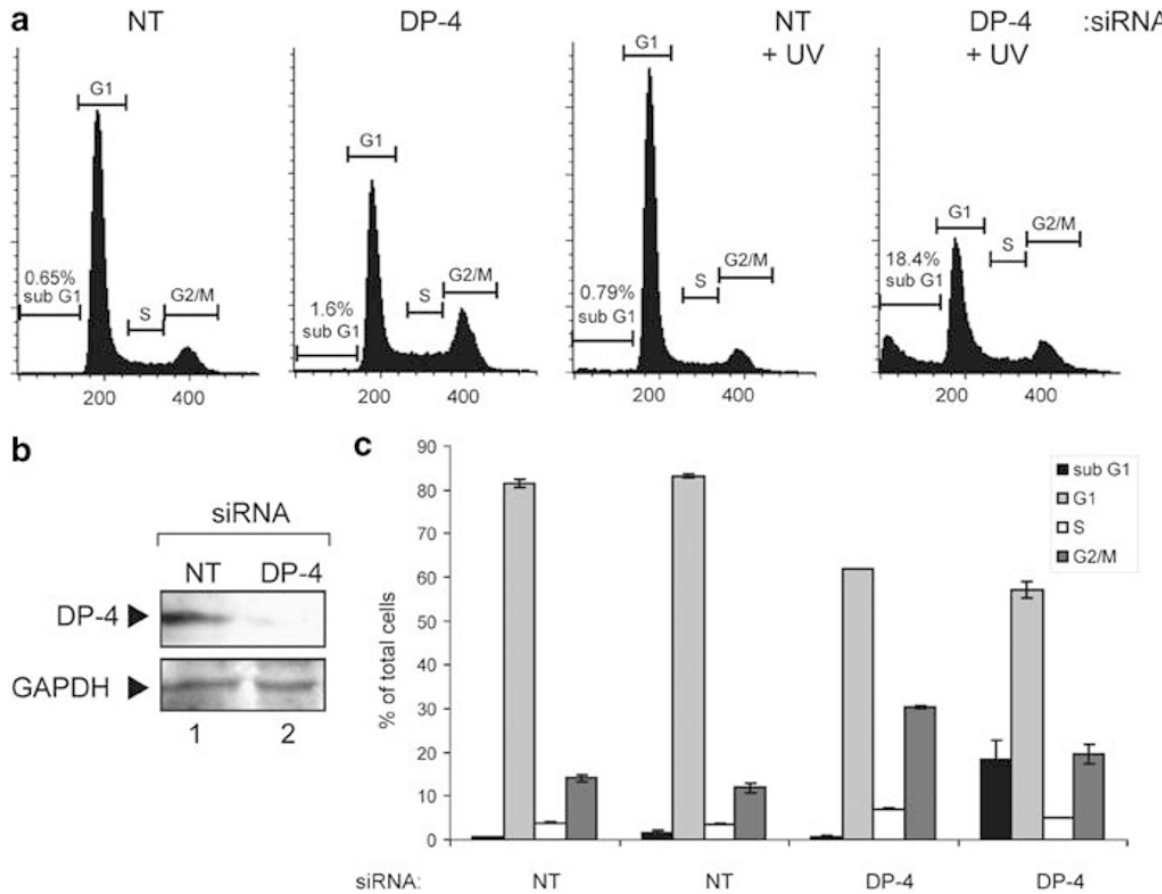

$$
\text { UV: }
$$

d

UV
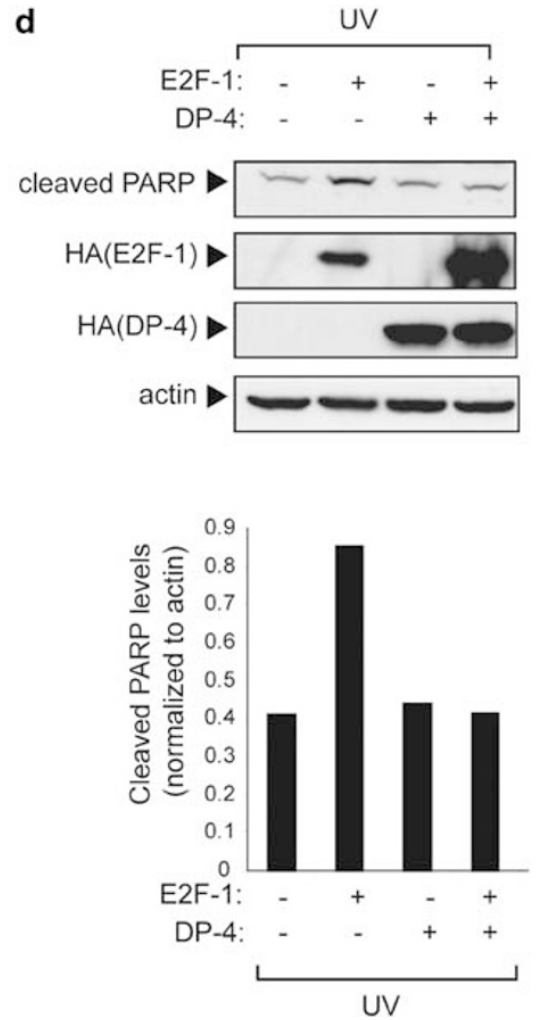

e

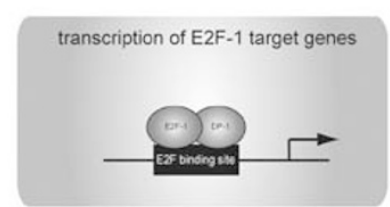

DNA damage

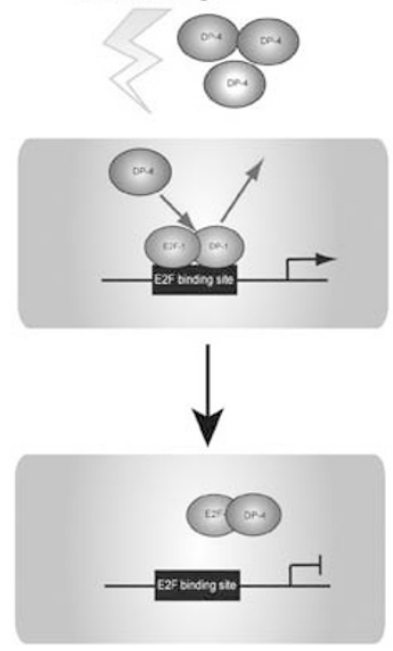

Figure 7 Cell cycle control by DP-4. (a) U2OS cells were treated with DP-4 or non-targeting (NT) siRNA. After $48 \mathrm{~h}$, cells were treated with ultraviolet (UV) light ( $50 \mathrm{~J} / \mathrm{m}^{2}$ ). After $8 \mathrm{~h}$, cells were analysed by flow cytometry (approximately $20000 \mathrm{cells}$ ). The flow cytometry profiles are shown, with the size of the sub-G1 fraction indicated. (b) Level of endogenous DP-4 in U2OS cells treated in (a), with GAPDH as loading control. (c) Graphical representation of the flow cytometry profiles shown in (a) according to cell cycle phase (sub-G1, G1, S or G2/M). (d) U2OS cells were transfected with expression vectors encoding E2F-1 $1 \mu \mathrm{g})$, DP-4 (1 $\mu \mathrm{g}$ ) or both, as indicated. After $72 \mathrm{~h}$, cells were treated with ultraviolet (UV) light $\left(50 \mathrm{~J} / \mathrm{m}^{2}\right)$. After $8 \mathrm{~h}$, cells were harvested, and the level of cleaved PARP (reflecting the level of apoptosis) was measured. Actin levels served as a loading control. Quantitation of cleaved PARP relative to actin control is shown in the graph below. (e) Model incorporating the properties of DP-4 involved in E2F-1 control. It is envisaged that DP-4 competes with DP-1, which in turn downregulates E2F-1 DNA-binding activity. This occurs both in normal and DNA-damaged cells in which DP-4 levels increase in response to DNA damage 
Negative regulation of E2F-1 independently of pRb. The properties of DP-4 define a new mechanism through which E2F-1 activity can be negatively regulated but, importantly, provide a pathway that operates in a pRb-independent manner. pRb and the related family members p107 and p130 bind to specific E2F subunits through a domain required for transcriptional activation, and the interaction prevents transcriptional activation by the E2F subunit. ${ }^{5,24}$ Under normal cell cycle conditions, the sequential phosphorylation of $\mathrm{pRb}$ directed by cyclin/Cdk complexes releases $\mathrm{pRb}$ from E2F-1, thereby facilitating the activation of E2F target genes. ${ }^{25}$ It is possible that the ability of DP-4 to hinder E2F-1 DNA-binding activity, and thereby limit the level of E2F-1-dependent transcription, provides an alternative biochemically distinct pathway for downregulating E2F-1 activity.

In conclusion, our results have unearthed an unexpected yet central role for DP-4 in regulating E2F-1 activity. DP-4 downregulates E2F-1, and the widespread expression of DP-4 suggests that this is a general mechanism used in many different types of cells. DP-4 therefore contributes to a new $\mathrm{pRb}$ independent mechanism for regulating cell cycle progression.

\section{Materials and Methods}

Plasmids and expression vectors. HA-DP-1, HA-DP-4 and HA-E2F-1 have been described previously. ${ }^{18}$ pCdc6-luciferase, ${ }^{26}$ p73-luciferase, ${ }^{27}$ Apaf1luciferase ${ }^{21}$ and pCyclinE-luciferase ${ }^{28}$ have also been described previously.

Anti-DP-4 peptide antibody. The rabbit polyclonal anti-DP-4 antibody was generated by Sigma (Sigma, Poole, UK). In briefly, a synthetic DP-4 peptide was generated containing residues 13-28 (C-ELKVLMDENQTSRPVC-C). This peptide was used to immunize rabbits. The resulting polyclonal antibody was purified by passing the crude antiserum through a DP-4 peptide column.

Tissue culture and transfection. U2OS, HeLa, HEK293, MCF7, H1299 and SAOS2 cells were cultured in Dulbecco's modified Eagle's medium (DMEM) (Invitrogen, Paisley, UK) supplemented with 10\% fetal bovine serum (FBS) and penicillin-streptomycin (Invitrogen) at $37^{\circ} \mathrm{C}$ in $5 \% \mathrm{CO}_{2}$. Cell lines were transfected with GeneJuice (Novagen, Nottingham, UK). For PARP cleavage, U2OS cells were transfected with expression vectors encoding HA-DP-4 or empty vector $(1 \mu \mathrm{g})$. After $40 \mathrm{~h}$, cells were treated with UV $\left(50 \mathrm{~J} / \mathrm{m}^{2}\right)$ for $8 \mathrm{~h}$

Immunoprecipitation and immunoblotting. Cells were harvested, washed in PBS and resuspended in TNN buffer $(50 \mathrm{mM}$ Tris $\mathrm{pH} 7.4,5 \mathrm{mM}$ EDTA, $0.5 \%$ Igepal CA-630 (Sigma), $50 \mathrm{mM} \mathrm{NaF}, 1 \mathrm{mM}$ DTT, $0.2 \mathrm{mM}$ Na3VO4, $120 \mathrm{mM} \mathrm{NaCl}$, protease inhibitor cocktail (Roche, Welwyn Garden City, UK)). Total protein concentration was determined using Bradford assay (Bio-Rad, Hemel Hempstead, UK). Typically $1-1.5 \mathrm{mg}$ of cell extract was added to pre-washed Protein-G agarose beads (Sigma) with $1 \mu \mathrm{g}$ of antibody. After overnight incubation, the beads were washed 4 times in TNN before protein elution with $2 \times$ SDS loading buffer and analysis by SDS-PAGE and immunoblotting with the appropriate antibodies. The following antibodies were used for immunoblotting; anti-HA11 (Covance, Denver, PA, USA), anti-proliferating cell nuclear antigen (PCNA), antilamin B, anti-E2F-1, anti-DP-1, anti-Cdc6, anti-Cdc2, anti-GAPDH (Santa Cruz, Santa Cruz, CA, USA), anti-PARP (BD Pharmingen, Franklin Lakes, NJ, USA) anti-nucleophosmin and anti-actin (Sigma).

Immunostaining. U2OS cells were stained according to previously published procedures. ${ }^{29}$

Cell fractionation. Cell fractionation was performed as previously described. ${ }^{30}$

Luciferase assays. For reporter assays, U2OS cells were transfected with $0.2 \mu \mathrm{g}$ of luciferase reporter plasmid, $0.2 \mu \mathrm{g}$ of pCMV- $\beta$-galactosidase ( $\beta$-gal) plasmid as an internal control and the indicated expression plasmids as previously described. ${ }^{31}$
Flow cytometry. U2OS cells were transfected with DP-4 siRNA or non-targeting (NT) control siRNA. After $72 \mathrm{~h}$, cells were treated with UV $50 \mathrm{~J} / \mathrm{m}^{2}$. After $8 \mathrm{~h}$, cells were washed in PBS and fixed overnight in $50 \%$ ethanol/PBS at $4^{\circ} \mathrm{C}$. Fixed cells were washed in PBS and incubated for $30 \mathrm{~min}$ with $25 \mathrm{U} / \mathrm{ml}$ RNase A (Sigma) and $50 \mu \mathrm{g} / \mathrm{ml}$ propidium iodide (Sigma) in PBS. The analysis of cell cycle profiles was performed as previously described. ${ }^{31}$

DP-4 siRNA treatment. Cells were transfected with $25 \mathrm{nM}$ DP-4 siRNA (5'-CAGAAGTGCTGATGTGGAT-3') or NT control no. 2 siRNA (Dharmacon, Chicago, IL, USA). Cells were transfected using Oligofectamine (Invitrogen).

Chromatin immunoprecipitation. U2OS cells were maintained in DMEM containing $10 \%$ fetal calf serum. Cells were transfected with the indicated plasmids or siRNA. Cells were cross-linked with formaldehyde to a final concentration of $1 \%$. ChIP samples were prepared as described previously. ${ }^{32}$ Immunoprecipitations were performed using $2 \mu \mathrm{g}$ anti-E2F-1 (KH95; Santa Cruz), anti-HA11 (Covance) or the relevant nonspecific (NS) IgG (Santa Cruz). The recovered DNA was analyzed using semiquantitative or real-time quantitative PCR. ${ }^{33}$ The primers used were as follows:

E2F-1 forward 5'-AGGAACCGCCGCCGTTGTTCCCGT-3', E2F-1 reverse 5'-GCTGCCTGCAAAGTCCCGGCCACT-3'; Cdc2 forward 5'-GCTTGCGCTCGCACT CAGTTGGCC-3', Cdc2 reverse $5^{\prime}$-CAGATCCCTGACCTCCAGTCC-3'; albumin forward $5^{\prime}$-TGGGGTTGACAGAAGAGAAAAGC-3' and albumin reverse $5^{\prime}$-TACA TTGACAAGGTCTTGTGGAG-3'.

Quantitative PCR. Real-time PCR for the ChIP was carried out according to the manufacturer's instructions using Brilliant II SYBR Green QPCR Master Mix (Agilent Technologies, Wokingham, UK).

RT-PCR. Total RNA was isolated using RNeasy Mini kit (QIAGEN, Crawley, UK). cDNA was synthesized from $1 \mu \mathrm{g}$ total RNA with SuperScript First-Strand Synthesis System (Invitrogen). Semiquantitative PCR was performed as described. ${ }^{32}$ The primers used were as follows: Cdc2 forward $5^{\prime}$-AATTGGAGAAGGTACCTATGGA-3', Cdc2 reverse 5'-TGTACTGACCAGGAGGGATA-3'; Apaf1 forward 5'-CACGTT CAAAGGTGGCTGAT-3', Apaf1 reverse 5'-TGGTCAACTGCAAGGACCAT-3'; p73 forward $5^{\prime}$-ACTTCAACGAAGGACAGTCTGCT- $3^{\prime}$ and p73 reverse $5^{\prime}$-AATTCC GTCCCCACCTGTG-3'

\section{Conflict of interest}

The authors declare no conflict of interest.

Acknowledgements. We thank the MRC, CRUK, EU, LRF and AICR for supporting this work and Rosemary Williams for assistance in preparing the paper.

1. Stevens C, La Thangue NB. E2F and cell cycle control: a double-edged sword. Arch Biochem Biophys 2003; 412: 157-169.

2. Trimarchi JM, Lees JA. Sibling rivalry in the E2F family. Nat Rev Mol Cell Biol 2002; 3 : $11-20$.

3. Bandara LR, La Thangue NB. Adenovirus-E1a prevents the retinoblastoma gene-product from complexing with a cellular transcription factor. Nature 1991; 351: 494-497.

4. Chellappan SP, Hiebert S, Mudryj M, Horowitz JM, Nevins JR. The E2F transcription factor is a cellular target for the RB protein. Cell 1991; 65: 1053-1061.

5. Dyson N. The regulation of E2F by pRB-family proteins. Genes Dev 1998; 12 : 2245-2262.

6. Frolov MV, Dyson NJ. Molecular mechanisms of E2F-dependent activation and pRB-mediated repression. J Cell Sci 2004; 117 (Part 11): 2173-2181.

7. Maiti B, Li J, de Bruin A, Gordon F, Timmers C, Opavsky R et al. Cloning and characterization of mouse E2F8, a novel mammalian E2F family member capable of blocking cellular proliferation. J Biol Chem 2005; 280: 18211-18220.

8. Di Stefano L, Jensen MR, Helin K. E2F7, a novel E2F featuring DP-independent repression of a subset of E2F-regulated genes. EMBO J 2003; 22: 6289-6298.

9. de Bruin A, Maiti B, Jakoi L, Timmers C, Buerki R, Leone G. Identification and characterization of E2F7, a novel mammalian E2F family member capable of blocking cellular proliferation. J Biol Chem 2003; 278: 42041-42049.

10. Logan N, Graham A, Zhao X, Fisher R, Maiti B, Leone G et al. E2F-8: an E2F family member with a similar organization of DNA-binding domains to E2F-7. Oncogene 2005; 24: 5000-5004. 
11. Logan N, Delavaine L, Graham A, Reilly C, Wilson J, Brummelkamp TR et al. E2F-7: a distinctive $\mathrm{E} 2 \mathrm{~F}$ family member with an unusual organization of DNA-binding domains. Oncogene 2004; 23: 5138-5150.

12. Bandara LR, Lam EW, Sorensen TS, Zamanian M, Girling R, La Thangue NB. DP-1: a cell cycle-regulated and phosphorylated component of transcription factor DRTF1/E2F which is functionally important for recognition by $\mathrm{pRb}$ and the adenovirus E4 orf $6 / 7$ protein EMBO J 1994; 13: 3104-3114.

13. Girling R, Partridge JF, Bandara LR, Burden N, Totty NF, Hsuan JJ et al. A new component of the transcription factor DRTF1/E2F. Nature 1993; 365: 468.

14. Kohn MJ, Bronson RT, Harlow E, Dyson NJ, Yamasaki L. Dp1 is required for extraembryonic development. Development 2003; 130: 1295-1305.

15. Krek W, Xu G, Livingston DM. Cyclin A-kinase regulation of E2F-1 DNA binding function underlies suppression of an S phase checkpoint. Cell 1995; 83: 1149-1158.

16. de la Luna S, Burden MJ, Lee CW, La Thangue NB. Nuclear accumulation of the E2F heterodimer regulated by subunit composition and alternative splicing of a nuclear localization signal. J Cell Sci 1996; 109 (Part 10): 2443-2452.

17. Ormondroyd E, de la Luna S, La Thangue NB. A new member of the DP family, DP-3, with distinct protein products suggests a regulatory role for alternative splicing in the cell cycle transcription factor DRTF1/E2F. Oncogene 1995; 11: 1437-1446.

18. Milton A, Luoto K, Ingram L, Munro S, Logan N, Graham AL et al. A functionally distinct member of the DP family of E2F subunits. Oncogene 2006; 25: 3212-3218.

19. Qiao H, Di Stefano L, Tian C, Li YY, Yin YH, Qian XP et al. Human TFDP3, a novel DP protein, inhibits DNA binding and transactivation by E2F. J Biol Chem 2007; 282: 454-466.

20. Tian C, Lv D, Qiao H, Zhang J, Yin YH, Qian XP et al. TFDP3 inhibits E2F1-induced, p53-mediated apoptosis. Biochem Biophys Res Commun 2007; 361: 20-25.
21. Moroni MC, Hickman ES, Lazzerini Denchi E, Caprara G, Colli E, Cecconi F et al. Apaf-1 is a transcriptional target for E2F and p53. Nat Cell Biol 2001; 3: 552-558.

22. Zheng N, Fraenkel E, Pabo CO, Pavletich NP. Structural basis of DNA recognition by the heterodimeric cell cycle transcription factor E2F-DP. Genes Dev 1999; 13: 666-674.

23. Iaquinta PJ, Lees JA. Life and death decisions by the E2F transcription factors. Curr Opin Cell Biol 2007; 19: 649-657.

24. van den Heuvel S, Dyson NJ. Conserved functions of the pRB and E2F families. Nat Rev Mol Cell Biol 2008; 9: 713-724.

25. Mittnacht S. Control of pRB phosphorylation. Curr Opin Genet Dev 1998; 8: 21-27.

26. Hateboer G, Wobst A, Petersen BO, Le Cam L, Vigo E, Sardet C et al. Cell cycle-regulated expression of mammalian CDC6 is dependent on E2F. Mol Cell Biol 1998; 18: 6679-6697.

27. Pediconi N, lanari A, Costanzo A, Belloni L, Gallo R, Cimino L et al. Differential regulation of E2F1 apoptotic target genes in response to DNA damage. Nat Cell Biol 2003; 5: 552-558.

28. Botz J, Zerfass-Thome K, Spitkovsky D, Delius $\mathrm{H}$, Vogt B, Eilers $\mathrm{M}$ et al. Cell cycle regulation of the murine cyclin $\mathrm{E}$ gene depends on an $\mathrm{E} 2 \mathrm{~F}$ binding site in the promoter. Mol Cell Biol 1996; 16: 3401-3409.

29. Markham D, Munro S, Soloway J, O'Connor DP, La Thangue NB. DNA-damageresponsive acetylation of pRb regulates binding to E2F-1. EMBO Rep 2006; 7: 192-198.

30. Coutts AS, Weston L, La Thangue NB. A transcription co-factor integrates cell adhesion and motility with the p53 response. Proc Natl Acad Sci USA 2009; 106: 19872-19877.

31. Chan HM, Krstic-Demonacos M, Smith L, Demonacos C, La Thangue NB. Acetylation control of the retinoblastoma tumour-suppressor protein. Nat Cell Biol 2001; 3: 667-674.

32. Zalmas LP, Zhao X, Graham AL, Fisher R, Reilly C, Coutts AS et al. DNA-damage response control of E2F7 and E2F8. EMBO Rep 2008; 9: 252-259.

33. Xu D, Zalmas LP, La Thangue NB. A transcription cofactor required for the heat-shock response. EMBO Rep 2008; 9: 662-669.

\section{Supplementary Information accompanies the paper on Cell Death and Differentiation website (http://www.nature.com/cdd)}

